\title{
In situ quantification of bioturbation using time-lapse fluorescent sediment profile imaging (f-SPI), luminophore tracers and model simulation
}

\author{
Martin Solan ${ }^{1, *}$, Benjamin D. Wigham ${ }^{2,6}$, Ian R. Hudson ${ }^{2}$, Robert Kennedy ${ }^{3}$, \\ Christopher H. Coulon ${ }^{4}$, Karl Norling ${ }^{5}$, Hans C. Nilsson ${ }^{5}$, Rutger Rosenberg ${ }^{5}$ \\ ${ }^{1}$ Oceanlab, School of Biological Sciences, University of Aberdeen, Newburgh, Aberdeenshire AB41 6AA, UK \\ ${ }^{2}$ DEEPSEAS group, George Deacon Division, Southampton Oceanography Centre, Empress Dock, European Way, \\ Southampton SO14 3ZH, UK \\ ${ }^{3}$ Martin Ryan Institute, National University of Ireland, Galway, Ireland \\ ${ }^{4}$ The GAIA Group, 2200 Roosevelt Avenue, Berkeley, California 94703, USA \\ ${ }^{5}$ Department of Marine Ecology, Goteborg University, Kristineberg Marine Research Station, 45034 Fiskebackskil, Sweden \\ ${ }^{6}$ Present address: Oceanlab, School of Biological Sciences, University of Aberdeen, Newburgh, Aberdeenshire AB41 6AA, UK
}

\begin{abstract}
In order to link actual biological data on bioturbation to the abstract parameters in bioturbation models, high-resolution data on the frequency and lengths of particle displacements are required. The temporal variation in bioturbation for a subtidal macrofaunal assemblage was studied non-invasively and in situ using an optically modified fluorescence sensitive time-lapse sediment profile imaging camera (f-SPI), fluorescent-dyed sediment particles (luminophores) and mathematical modelling. This combined approach allowed tracer particles to be non-invasively tracked and their displacements monitored at an unprecedented spatial $(78 \mu \mathrm{m})$ and temporal (every $10 \mathrm{~min}$ ) resolution for extended periods of time $(16 \mathrm{~h})$. The redistribution of luminophores was digitally acquired from sequential images and compared to model predictions, with particle transport modelled as (1) a diffusive process, allowing the biodiffusion coefficient, $D_{\mathrm{b}}$, to be estimated, and (2) a non-local process, allowing a reworking activity constant, $a$, to be calculated. Model predictions of luminophore particle transport for the final image of the f-SPI sequence gave: $D_{\mathrm{b}}=1.26 \times 10^{2} \mathrm{~cm}^{2} \mathrm{yr}^{-1} ; a=5.23 \times$ $10^{-2} \mathrm{~cm}^{-1} \mathrm{yr}^{-1}$. Discrete values of a fluctuated widely throughout the sequence and allowed discrete bioturbation events to be identified. Time-lapse movie sequences revealed that most of the bioturbation observed during the deployment could be directly attributed to the behaviour of the brachyuran crab Hyas araneus. Our findings demonstrate that f-SPI provides a rapid and non-invasive means to visualise and quantify, in situ, the extent and influence of discrete infaunal bioturbation events on particle mixing. This technique provides detailed information on the spatial and temporal resolution of such bioturbation events, which could significantly improve existing models of bioturbation.
\end{abstract}

KEY WORDS: Sediment profile imaging · Luminophore tracer - Bioturbation · Biodiffusion coefficient · Reworking activity constant $\cdot$ Non-local modelling $\cdot$ Benthic

\section{INTRODUCTION}

The mixing of porewater solutes and sediment particles by the activities of benthic organisms, collectively referred to as bioturbation (sensu Richter 1952), has long been known to have profound effects on the physical, chemical and biological properties of un- consolidated sediments (e.g. Gray 1974, Rhoads 1974, Aller 1982, Rhoads \& Boyer 1982). Through burrowing, feeding, ventilatory and locomotory behaviour, the infauna disproportionately influence biogeochemical and diagenetic reactions within the interstitial porewater and promote the vertical and lateral redistribution of sediment particles above and/or below the sedi- 
ment-water interface. Although the precise form and rate of bioturbation is generally species-specific (e.g. Forster \& Graf 1995, Shull \& Yasuda 2001) and may covary with respect to other environmental variables (e.g. Solan \& Kennedy 2002, Biles et al. 2003), the combined effect of infaunal activity on the properties of the sediment has important implications for many ecosystem processes; bioturbation directly affects organic matter remineralisation and decomposition (Anderson \& Kristensen 1991, Aller 1994), nutrient cycling (Furukawa et al. 2001), pollutant release (Gilbert et al. 1994), sediment resuspension (Rowden et al. 1998) and microbial activity (Aller \& Yingst 1985). Understanding and quantifying the mechanisms of bioturbation is therefore of primary importance in disentangling organismsediment interactions as they relate to the provision and long-term sustainability of ecosystem function.

Several direct approaches have been used for estimating the extent of bioturbation, including the collection of burrow ejecta (Cadée 1976), faecal pellets (Hughes et al. 1996) and resin casts (Meadows \& Tufail 1986), although these methods have gradually been superseded by the use of natural and artificial tracers (e.g. glass beads, isotopically labelled algae, inert solutes, radionuclides, metal-doped sediment and fluorescent luminophores; Wheatcroft et al. 1994, Blair et al. 1996, Gerino et al. 1998, Sandnes et al. 2000, Berg et al. 2001, Green et al. 2002, Forster et al. 2003). The use of such tracers allows the average concentration of particles within the sediment profile to be characterised following a short incubation period, but the process of tracer recovery can be extremely time consuming and is not without error. Replicate cores containing luminophore particles, for example, are usually sliced into horizontal segments ( $1 \mathrm{~cm}$ thick), each of which undergoes a series of washing and sieving steps to remove the fine fraction of the sediment, before the remaining sediment is dried in an oven and the luminophores are manually counted under an ultraviolet light source (e.g. Gerino et al. 1998). During this process, there is a risk that the sediment may be mixed between segments, or that the porewater may drain from one segment to another, thereby artificially extending the tracer profile to result in an overestimate of the degree of mixing (Berg et al. 2001). Even when it is anticipated that this has not taken place, it is unlikely that the behaviour of infauna confined within a narrow core is representative of the natural situation in the field (e.g. Jones \& Jago 1993). Despite these issues, the use of tracers remains the best currently available method for obtaining the necessary information required to quantify and compare rates of sediment reworking with mathematical models of bioturbation (e.g. Boudreau 1986, Boudreau \& Imboden 1987, François et al. 1997, 2002; and for review see Meysman et al. 2003).
The most commonly used model descriptor of bioturbation is the biodiffusion coefficient $D_{\mathrm{b}}$, which typically ranges between $10^{2}$ and $10^{-3} \mathrm{~cm}^{2} \mathrm{yr}^{-1}$ for macrofaunal assemblages in subtidal sediments (Matissoff 1982; for exceptions, see Green et al. 2002). While values of $D_{\mathrm{b}}$ provide a convenient and useful means to compare bioturbation rates, the assumptions underlying a biodiffusive analogy are over-simplistic; it is presupposed that particles randomly move over short distances and that the rate of such movement is proportional to the tracer concentration gradient. As many species are capable of transporting particles over distances equal to, or even greater than, their own body lengths (e.g. through upward or downward conveyor belt feeding, Fisher et al. 1980; burrow and fill mixing, Boudreau \& Imboden 1987; or sediment regeneration, Gardner et al. 1987), such an assumption is simply inappropriate. Indeed, the application of biodiffusive models has provided little predictive understanding of bioturbation for the following main reasons (modified from François et al. 1997): (1) a diffusive analogy is constrained by the conditions of the symmetry and length criteria, which often do not reflect the frequency and length scales of discrete bioturbation events imposed by species behaviour, (2) the currently employed techniques for tracer studies are integrative measures, and thus not able to separate or document a series of discrete rapid mixing events over a long period of time (e.g. Wheatcroft et al. 1990), and (3) variation in the rate of tracer mixing cannot be directly related to specific bouts of animal activity; the poor connection between 'real' biological activity and parameter values in bioturbation studies is a major weakness in the interpretation of model data. While many of these issues can be avoided through the use of a theoretical framework based on a non-local model of tracer redistribution (e.g. Boudreau 1986, Boudreau \& Imboden 1987), the main problem in the interpretation of bioturbation profiles remains: Specific sediment reworking signatures obtained within tracer profiles cannot always be matched with individual species, nor can they be directly associated with interactions between individuals or external environmental phenomena.

One method that has proven successful in observing and interpreting dynamic processes below the sediment-water interface is time-lapse sediment profile imaging (t-SPI; see Diaz \& Cutter 2001, Solan \& Kennedy 2002). This technique provides multiple undisturbed cross-sectional images of the benthos, obtained in situ, that simultaneously allow the visual identification of species and the direct observation of anecdotal and quantifiable information on infaunal activity. It follows that the expansion of this technique to incorporate an ability to visualise an optically distinct tracer, such as a luminophore, would allow tracer 
activity to be directly associated with discrete bioturbation events and/or matched to the activities of individual species visible in the images. Some progress towards this goal has already been made. Gilbert et al. (2003) successfully used images from a series of laboratory cores containing luminophores to calculate an optical reworking coefficient $(\overline{\Delta Q})$ using standard image analysis routines. Although the calculation of $\overline{\Delta Q}$ was unable to derive realistic and comparable rates of bioturbation, it demonstrated the viability of the imaging approach. The aim of the present study was: (1) to combine the use of an optically distinct tracer with in situ t-SPI, (2) simultaneously visualise infaunal behaviour and quantify tracer activity for a subtidal assemblage, (3) communicate a method of modelling the observed behaviour, and (4) ensure that the spatial and temporal resolution was sufficient to capture rapid and/or discrete bioturbation events.

\section{MATERIALS AND METHODS}

Sediment profile imaging. A time-lapse capable sediment-profile imaging camera was optically modified (see below) for fluorescence detection and deployed in $28 \mathrm{~m}$ water depth at Gullsmarsfjord, Sweden (58 $\left.15^{\prime} 252^{\prime \prime} \mathrm{N}, 11^{\circ} 27^{\prime} 158^{\prime \prime} \mathrm{E}\right)$; a site known to contain many important bioturbators, including Amphiura filiformis, Echinocardium cordatum and Calocaris macandreae. The SPI consists of a stainless steel support frame and a prism-shaped imaging module that penetrates the sediment-water interface when lowered on a wire from a vessel. The back plate of the prism contains a mirror mounted at a $45^{\circ}$ angle that reflects the sediment profile up to the camera (for general principles, see Rhoads \& Cande 1971). The current imaging module on the SPI houses a Canon EOS D60 single lens reflex digital CMOS camera $(2048 \times 3072$ pixels, i.e. 6.29 megapixels) equipped with an $\mathrm{f} 2.0 \mathrm{Canon} \mathrm{EF}$ $35 \mathrm{~mm}$ lens, an automated interval timing facility and a modified flash (ETTL Canon 220 EX). The camera was set for an exposure of 1/60, $f=4.0$ and a film speed of ISO 200. The dimensions of the prism face-plate allow a maximum visible area of $384 \mathrm{~cm}^{2}(16 \times 24 \mathrm{~cm})$ to be imaged. This configuration provides an effective image resolution of $78.13 \times 78.13 \mu \mathrm{m}$ per pixel. The SPI camera was placed in situ approximately $2 \mathrm{~h}$ prior to the start of the time-lapse sequence and was uncoupled from the research vessel for the duration of the deployment.

The time-lapse sequence started at 09:58 h on 28 April 2003 and ended at $01.58 \mathrm{~h}$ on 29 April 2003 (i.e. $16 \mathrm{~h}$ ). Each successive image was taken at an interval of 10 min, giving a total of 97 images. Immediately after the first image, a team of SCUBA divers spread
$30.0 \mathrm{~g}$ dry weight of sand-based luminophores (i.e. natural sediments treated with a dye that fluoresces in ultraviolet light, Mahaut \& Graf 1987) on the sediment surface to aid subsequent visualisation of particle movement. The spread of luminophores was restricted to within $1 \mathrm{~cm}$ of the SPI face plate to form a layer approximately $3 \mathrm{~mm}$ deep. The luminophores (pink, 125 to $250 \mu \mathrm{m}$ diameter; Environmental Tracing Systems) were pre-soaked and vigorously shaken in seawater $24 \mathrm{~h}$ prior to distribution to prevent particle aggregation and/or floatation during the distribution process in the field. To maximise the distinction between luminophore particles and the surrounding sediment, lighting filters (Lee Filters, UK) were added to the camera lens (Medium yellow \#010) and flash (J. Winter Blue, \#713). The blue filter on the flash allows the transmission of light necessary for luminophore excitation ( $\lambda=375$ to $500 \mathrm{~nm}$ ) and for partial illumination of the sediment profile $(\lambda=700$ to $800 \mathrm{~nm})$, but blocks the transmission of any additional light. Reflected light returning to the camera passes through the yellow filter. This removes the light used solely for the purpose of luminophore excitation $(\lambda=375$ to 480 $\mathrm{nm})$, but allows the remaining light ( $\lambda=480$ to 500 and 700 to $800 \mathrm{~nm}$ ) through to the camera. This configuration allows accurate discrimination of luminophore particles while also retaining sufficient detail of the sediment profile. At the end of the time-lapse period, a $0.1 \mathrm{~m}^{2}$ Smith-MacIntyre grab was used to recover the sediment immediately in front of the camera face-plate. The sediment was washed through a standard $1.0 \mathrm{~mm}$ square mesh sieve. The fauna retained on the sieve was regarded as indicative of the macrofauna on station and was used to aid visual identification of any species observed in the SPI images.

Image analysis. Images were saved in red-green-blue (RGB) colour with JPEG (Joint Photographic Experts Group) compression (Fig. 1a). These were analysed using a custom-made semi-automated macro that runs within ImageJ (Version 1.30), a java-based public domain program developed at the US National Institutes of Health (available at http://rsb.info.nih.gov/ij/ index.html). The macro sequentially opens each image and converts it to an RGB stack. First, the user is presented with the second (green) slice, the most effective layer for the visual discrimination of the sedimentwater interface, and manually traces it with the segmented line tool. The segmented line serves as the upper limit of the region of interest (ROI) for all subsequent analyses. Next, the user is presented with the first (red) slice for manually selecting the luminophores using an appropriate threshold level that distinguishes the target particles from the background sediment. The thresholded image is automatically converted to a bitmapped image $(0=$ background sediment, $255=$ 

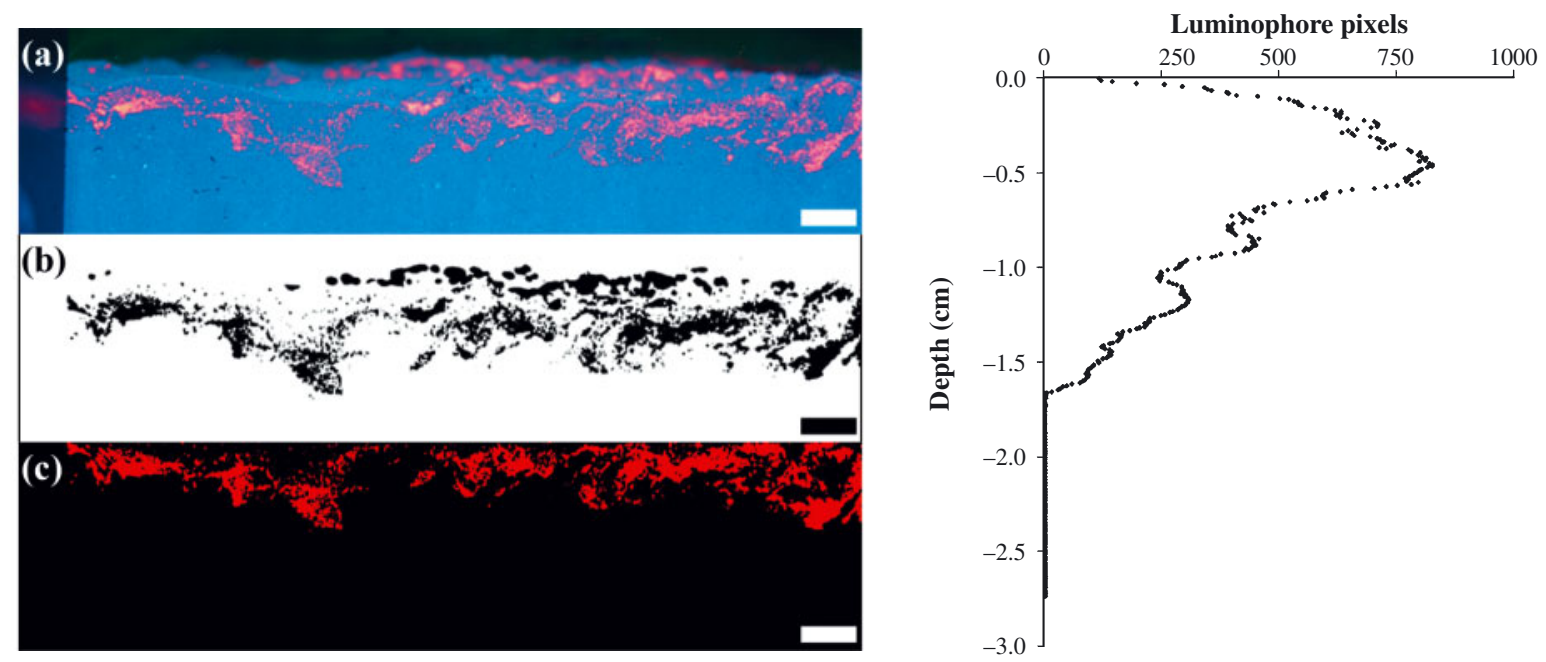

(d)

Fig. 1. The process of image analysis for the optical quantification of luminophores showing (a) the original image with the sediment appearing in blue and luminophore particles in pink, (b) the thresholded image, and (c) the processed image, corrected so that the sediment-water interface is flattened and all luminophore pixels on the sediment surface have been discarded.

In (d), the total number of luminophore pixels with depth are presented. Images have been cropped. Scale bars $=1.0 \mathrm{~cm}$

luminophore pixels; Fig. 1b) before the macro uses the $x$ - and $y$-coordinates of the segmented line to calculate every $y$-position along the $x$-axis and determine the pixel values for each $y$-column. The latter are transferred to an array that resets the starting index of each column to zero, i.e. the segmented line is flattened so that the sediment-water interface is equal to the first row of the array (Fig. 1c). Finally, the pixels that are equal to 255 for each row ( $x$-axis) of the array are summed to yield the total number of luminophore pixels for each value of $y$ (=depth) and are presented in a results table (Fig. 1d). These data were used to determine particle mixing rates using 2 separate models: biodiffusive and non-local (= advective). The initial layer of deposited tracers was $0.297 \mathrm{~cm}$ (= 38 pixel rows) deep. Luminophore counts were aggregated into boxes equal to this depth for modelling purposes. Luminophore pixel counts were converted to relative concentrations (i.e. expressed as a proportion of those recovered from each individual image) by dividing the number of luminophore pixels in each box by the total number of luminophore pixels in the image.

Biodiffusive modelling. The biodiffusion coefficient $\left(D_{\mathrm{b}}\right)$ was determined for the luminophore tracer counts from the final image in the time series using the 1-dimensional diffusion model, applicable for passive tracers in the absence of sedimentation and given by Crank (1975) as:

$$
\frac{\partial^{2} C}{\partial t}=D_{\mathrm{b}} \frac{\partial^{2} C}{\partial z^{2}}
$$

where $C$ is the relative concentration of luminophore pixels, $t$ is time and $z$ is depth (positive into the deposit).
The solution to Eq. (1) was determined by Crank (1975) to be:

$$
C(z, t)=C_{0} \exp \left(\frac{-z^{2}}{4 D_{\mathrm{b}} t}\right)
$$

where $C(z, t)$ is the tracer concentration at depth $z$ and time $t$, and $C_{0}$ is the relative concentration at $z=0$.

For consistency with the non-local model presented in the present study, Eq. (2) is rewritten here in terms of mass concentration. The initial condition is that of a tracer pulse at the sediment-water interface, i.e.

$$
C(z, 0)=M \delta(z)
$$

where $M$ denotes the amount of luminophores applied. Here, $\delta(z)$ denotes the Dirac delta function, which vanishes everywhere except at $z=0$, where it becomes infinite. The conversion of mass demands that at all times the total inventory of tracer in the sediment is equal to the amount initially applied, i.e.:

$$
\int_{0}^{\infty} C(z, 0) \mathrm{d} z=\int_{0}^{\infty} M \delta(z) \mathrm{d} z=M
$$

The upper boundary condition prevents the loss of luminophores to the water column, while at infinite depth (i.e. the lower boundary condition), luminophore concentration vanishes:

$$
\text { Upper boundary condition: }\left.\frac{\partial \mathrm{C}}{\partial \mathrm{z}}\right|_{z=0}=0
$$

$$
\text { Lower boundary condition: } \lim _{\mathrm{z} \rightarrow \infty} C(z, t)=0
$$

The solution to Eq. (1) then becomes:

$$
C(z, t)=\frac{M}{\sqrt{\pi D_{\mathrm{b}} t}} \exp \left(\frac{-z^{2}}{4 D_{\mathrm{b}} t}\right)
$$


$D_{\mathrm{b}}$ was derived by weighted least-squares regression of predicted profiles on observed tracer concentrations (François et al. 2002). This procedure calculates a squared residual between the observed (obs) and predicted (pred) concentrations at each depth. Each residual is weighted by the corresponding observed concentration +1 , to prevent a null denominator. A regression coefficient $(r)$ is calculated by summing the residuals as follows:

$$
r=\sum_{i=1}^{n} \frac{\left(\mathrm{obs}_{i}-\operatorname{pred}_{i}\right)^{2}}{\operatorname{obs}_{i}+1}
$$

This procedure attempts to give due consideration to the deeper sediment layers, where values of tracer concentration are typically low relative to the surface layers. Where the predicted profile is a perfect match with the observed profile, $r=0$.

Non-local modelling. Non-local transport coefficients were calculated for each image using a symmetric non-local model in the form:

$$
\frac{\partial C}{\partial t}=\int_{0}^{\infty} K\left(z^{\prime}, z\right) C\left(z^{\prime}, t\right) \mathrm{d} z^{\prime}-\int_{0}^{\infty} K\left(z, z^{\prime}\right) C(z, t) \mathrm{d} z^{\prime}
$$

where $K\left(z^{\prime}, z\right)$ represents the exchange function (Boudreau 1986, Boudreau \& Imboden 1987, Meysman et al. 2003) that models the non-local displacement rate of luminophores from a given depth $z^{\prime}$ to the modelling depth $z$. For simplicity, the exchange function was assumed to be symmetric, i.e.:

$$
K\left(z^{\prime}, z\right)=K\left(z, z^{\prime}\right)
$$

It was also assumed that the exchange decreased exponentially with distance. An explicit expression for the exchange function is given by:

$$
K\left(z^{\prime} z\right)=\operatorname{aexp}\left(-\frac{\left|z-z^{\prime}\right|}{\lambda}\right)
$$

where $a$ is a reworking activity constant (dimensions $\mathrm{L}^{-1} \mathrm{~T}^{-1}$ ), and $\lambda$ is the attenuation constant of the exponential function (dimensions $\mathrm{L}$ ). Here we used a fixed attenuation depth of $\lambda=3 \mathrm{~cm}$. This scale was larger than the total length of the transport observed in the SPI images. As for the biodiffusion model, an initial condition of a tracer pulse at the sediment-water interface was applied; however, the boundary conditions were changed to the following:

$$
\begin{aligned}
& \text { Upper boundary condition: }\left.\frac{\partial C}{\partial z}\right|_{z=0}=0 \\
& \text { Lower boundary condition: }\left.\frac{\partial C}{\partial z}\right|_{z=L}=0
\end{aligned}
$$

where $L$ represents the depth of the modelled sediment $(2.673 \mathrm{~cm})$.

The values of a producing the best fit were determined by weighted least-squares regression of the predicted profile to the observed mean profiles, as for the biodiffusive model.

\section{RESULTS}

The macrofaunal returns from the Smith-MacIntyre grab consisted of 122 individuals (53.0 g wet weight biomass), representing 12 taxa (Table 1). The most abundant faunal element were the ophiuroids Amphiura spp. (63.1\%), comprising 2 species: A. filiformis and A. chiajei. As these are largely indistinguishable in SPI images, they were not identified to species level. The bivalves Abra nitida (17.1\%) and Corbula gibba $(4.1 \%)$ and the polychaete Nephtys hombergii $(5.7 \%)$ were also relatively abundant. The remaining taxa, although less numerous, revealed the presence of some other major bioturbators on station (e.g. Echinocardium cordatum and Calocaris macandreae). In terms of biomass, E. cordatum and Amphiura spp. collectively accounted for $98.7 \%$ total biomass (Table 1 ).

Images from the f-SPI sequence showed no evidence of current-induced erosion or deposition at the sediment-water interface, although an undetermined amount of excess luminophores in the distant field of view did appear to be scoured away over the course of the deployment. Comparison of the pre- and postluminophore images (i.e. Frames 1 and 2 or -10 and $0 \mathrm{~min}$ ) confirmed that the act of luminophore emplacement did not disturb the sediment profile and that the spread of the luminophore deposit was satisfactory (i.e. tracers were homogeneously located along the sediment-water interface at time zero). Very little infaunal bioturbation was evident below the sediment-water interface, except for the brief appearance of one individual Nephtys hombergii at depth and a number of small horizontal burrows of unknown identity near the sediment surface. None of these biogenic structures resulted in a significant displacement of luminophores. Instead, almost all the observed bioturbation could be directly attributed to the presence of the brachyuran spider crab Hyas araneus.

The images reveal that Hyas araneus was present from at least 70 min (Frame 9) from the start of the sequence through to an elapsed time of 850 min (Frame 87), with regular occurrences in the images throughout the deployment (Frames 17, 19, 30, 48 to 55 and 86). Distinguishing marks on the walking legs (peraeopods) of the organism indicated the presence of at least 2 individuals during the sequence. Of the 13 frames in which $H$. araneus was visible, only 2 images (Frames 86 to 87 ) referenced the second individual. The regularity with which the first individual was documented, and its appearance within 2 frames of a distinctive bioturbation event (Frame 17 or $150 \mathrm{~min}$ ), suggest that this individual is 
Table 1. Summary of the macrofaunal returns from a $0.1 \mathrm{~m}^{2}$ Smith-MacIntyre grab obtained from immediately in front of the sediment profile imaging (SPI) face-plate at the end of the time-lapse sequence. Data are listed in descending order of abundance

\begin{tabular}{|lcccr|}
\hline Species & Abundance & $\begin{array}{c}\text { Biomass } \\
(\mathrm{g})\end{array}$ & $\begin{array}{c}\text { \% Total } \\
\text { abundance }\end{array}$ & $\begin{array}{r}\text { \% Total } \\
\text { biomass }\end{array}$ \\
\hline Amphiura spp. & 77 & 9.9847 & 63.11 & 18.85 \\
Abra nitida & 21 & 0.1023 & 17.21 & 0.19 \\
Nephtys hombergii & 7 & 0.1107 & 5.74 & 0.21 \\
Corbula gibba & 5 & 0.0066 & 4.10 & 0.01 \\
Melinna cristata & 2 & 0.0137 & 1.64 & 0.03 \\
Abra alba & 2 & 0.0083 & 1.64 & 0.02 \\
Cylichna cylindracea & 2 & 0.0053 & 1.64 & 0.01 \\
Risoella spp. & 2 & 0.0046 & 1.64 & 0.01 \\
Echinocardium cordatum & 1 & 42.307 & 0.82 & 79.89 \\
Calocaris macandreae & 1 & 0.3976 & 0.82 & 0.75 \\
Anaitides sp. & 1 & 0.0107 & 0.82 & 0.02 \\
Turritella communis & 1 & 0.0049 & 0.82 & 0.01 \\
Total & 122 & 52.9564 & 100.00 & 100.00 \\
\hline
\end{tabular}

primarily responsible for the observed redistribution of luminophores. Closer examination of the images revealed the mechanism of particle displacement (Fig. 2). When $H$. araneus remains stationary on the sediment surface, the walking legs penetrate the sediment-water interface (Fig. 2a). The individual appears to constantly adjust its posture during such rest periods, thereby palpating the sediment as each walking leg is re-positioned (Fig. 2b). As the individual relocates, the body rises and assumes an elevated position with respect to the sediment surface and it fully retracts each walking leg to enable forward motion (Fig. 2c). Measurements taken from the image estimate a body size of approximately 4.0 to $4.5 \mathrm{~cm}$ (posterior carapace width), a walking leg diameter of $0.5 \mathrm{~cm}$ and an apparent leg penetration depth of 1.5 to $2.0 \mathrm{~cm}$; the insertion angle of each walking leg into the sediment profile varied ( 7.5 to $30^{\circ}$ ) and was an unreliable indication of maximum penetration or subsurface orientation. Assuming the buried portion of each leg to be a cylinder $(\varnothing=0.5 \mathrm{~cm}$, length $=1.5 \mathrm{~cm})$, the volume of sediment displaced by 8 walking legs each time the organism relocates may be $\sim 2.36 \mathrm{~cm}^{3}$.

Sequential images allowed the transport of individual particles and the evolution of the tracer profile to be tracked (Fig. 3) and quantified (Fig. 4). For the first image of the sequence (Frame 2; Figs. 3a \& 4a), all luminophores were contained within the uppermost $0.30 \mathrm{~cm}$ of the sediment profile, reflecting the depth of the luminophore layer on the sediment surface. Burial of luminophore particles below this depth did not occur for at least 70 min (Frame 9), but this period was followed by a series of dramatic particle burial events. By $80 \mathrm{~min}$ (Frame 10), luminophores were present to a depth of $1.04 \mathrm{~cm}$, although a comparatively small number of particles (3531 to 8903 luminophore pixels, Frames 10 to 16) were buried below the $0.30 \mathrm{~cm}$ horizon (e.g. Figs. $3 \mathrm{~b} \& 4$ b). The latter, however, increased by an order of magnitude (to $44671 \mathrm{lu}$ minophore pixels) after $150 \mathrm{~min}$ (Frame 17), and was accompanied by an increase in the maximum luminophore penetration depth to $1.68 \mathrm{~cm}$ (e.g. Figs. 3c \& $4 \mathrm{c})$. The form of the luminophore profiles with depth (Figs. 3d-i \& 4d-i) shows that several non-local mixing events with length scales of whole $\mathrm{cm}$ per $10 \mathrm{~min}$ (equivalent to $10^{4} \mathrm{~cm} \mathrm{yr}^{-1}$ ) took place throughout the deployment period. Following these events, tracers were rapidly dispersed throughout the profile, leading to an approximately Gaussian, or biodiffusive, profile.

Model predictions of luminophore particle transport as a diffusive process on the final image (Frame 97) of the f-SPI sequence gave a $D_{\mathrm{b}}$ value of $1.26 \times 10^{2} \mathrm{~cm}^{2}$ $\mathrm{yr}^{-1}$. Although the predicted diffusional profile $\left(P_{\text {diff }}\right)$ statistically fitted reasonably well $(\mathrm{r}=0.079)$ with that
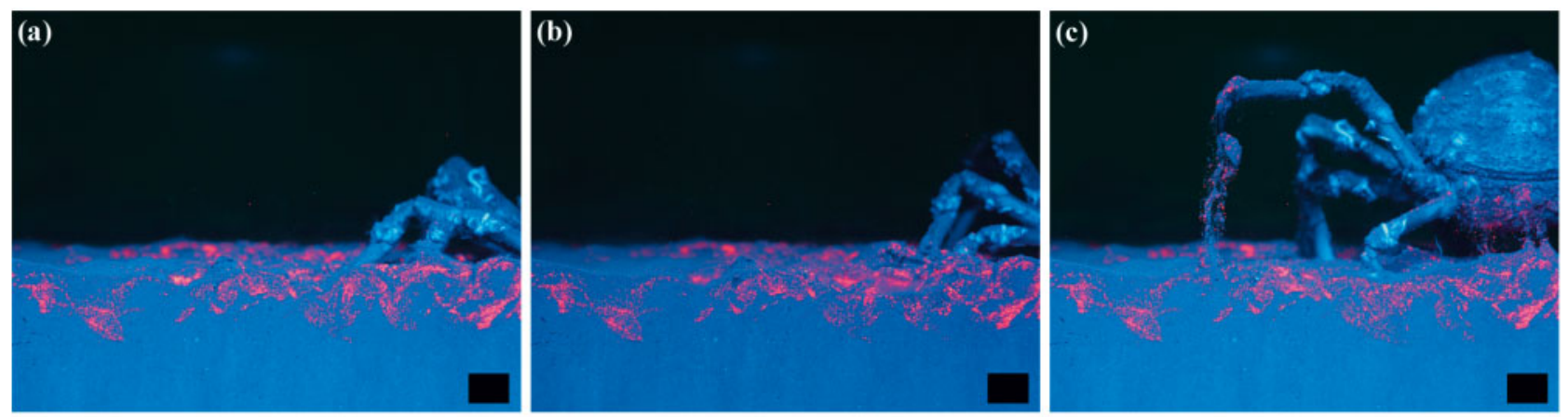

Fig. 2. Hyas araneus. Time-lapse sequence illustrating the repositioning behaviour of the spider crab. Walking legs penetrate below the sediment-water interface during periods of rest (a) but are constantly readjusted to maintain posture (b) or removed from the sediment when moving to a new location (c). Images represent (a) Frame 52 (500 min), (b) Frame 53 (510 min) and

(c) Frame 54 (520 min) and have been cropped. Scale bars $=1.0 \mathrm{~cm}$ 


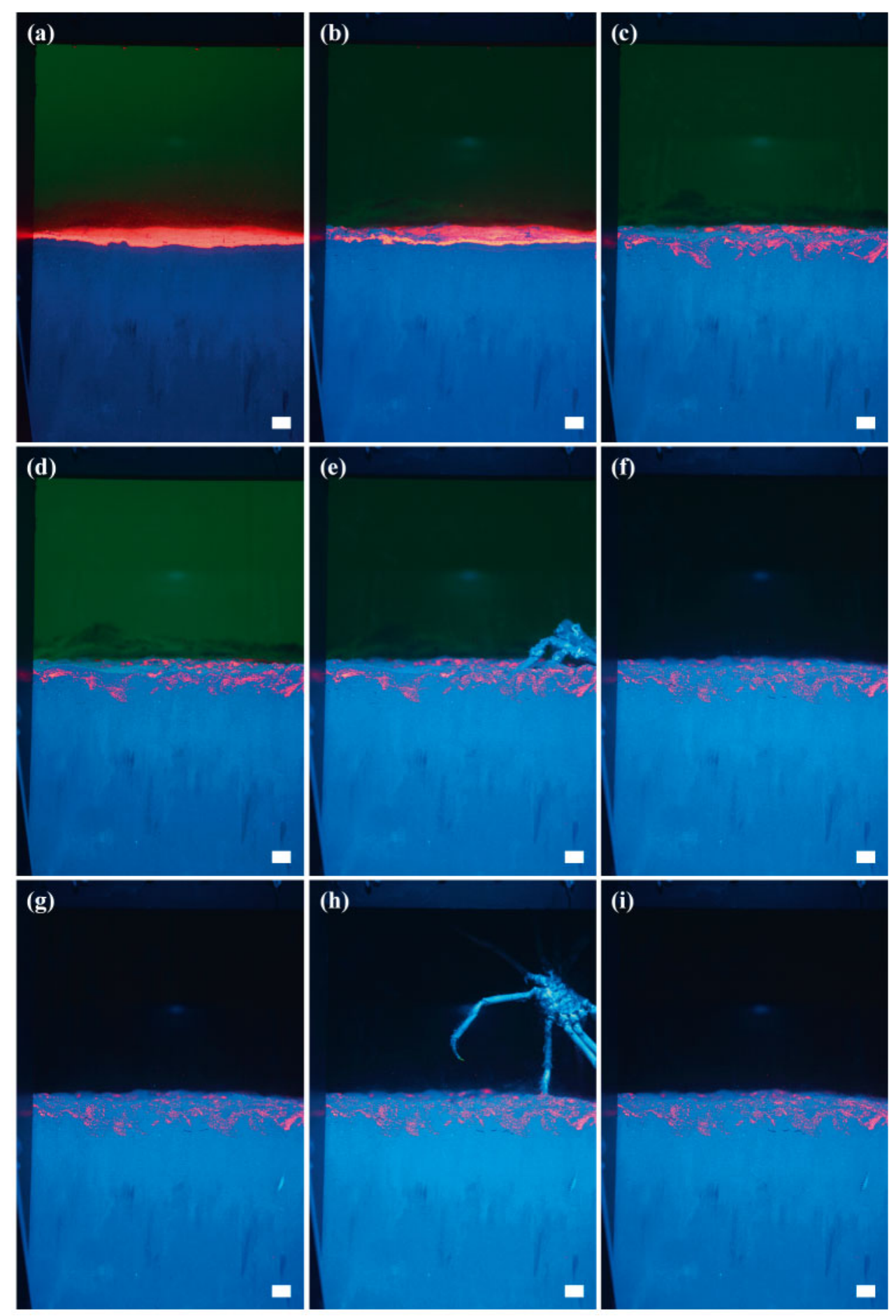

Fig. 3. Selected images from the time-lapse sequence detailing the impact of bioturbation on luminophore particle displacement from (a) Frame 2 (0 min) through to (i) Frame 97 (950 min). Intervening images (b to $h$ ) are each separated by 14 frames (=120 min). Sediment particles appear as blue and luminophore particles as pink. The presence of Hyas araneus can be seen in frames (e) and $(\mathrm{h})$. Scale bars $=1.0 \mathrm{~cm}$

\section{(g)}

of the observed profile $\left(P_{\text {obs }}\right)$, the form of the 2 profiles were not equivalent to one another; the degree of particle burial for $P_{\text {diff, }}$, when compared to $P_{\text {obs, }}$, was overestimated near to the sediment surface, and underestimated with increasing error with depth (Fig. 5). This disparity resulted in a difference in relative concentration of 2 orders of magnitude between $P_{\text {obs }}$ and $P_{\text {diff }}$ at a sediment profile depth of only $1.63 \mathrm{~cm}$. Below this depth, the biodiffusive model predicted relative concentrations below the detection limit of the technique. Use of the non-local model to predict particle transport for the same image (Frame 97) gave a reworking activity constant value of $5.23 \times 10^{-2} \mathrm{~cm}^{-1} \mathrm{yr}^{-1}$, but this prediction $\left(P_{\mathrm{nl}}\right)$ fitted the $P_{\mathrm{obs}}$ better $(\mathrm{r}=0.005)$ than the 
(a)

Relative concentration

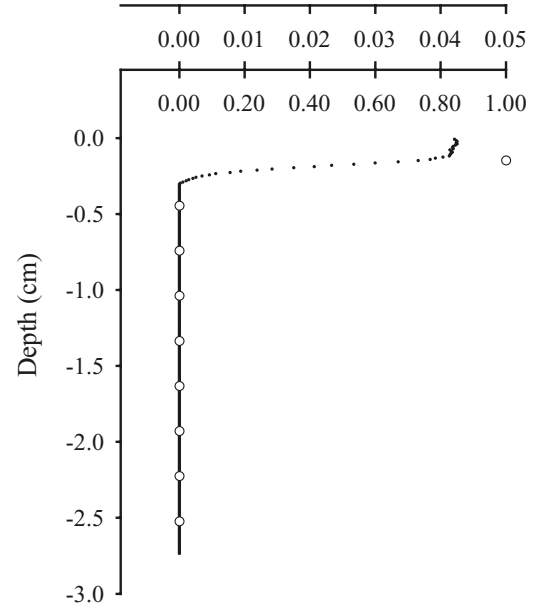

(d)

Relative concentration

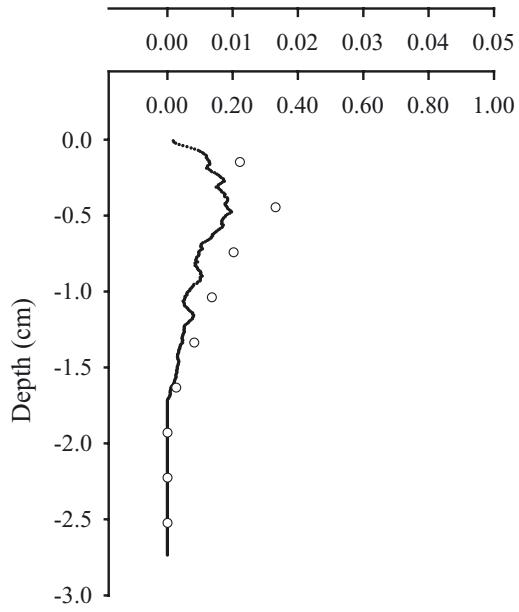

(g)

Relative concentration

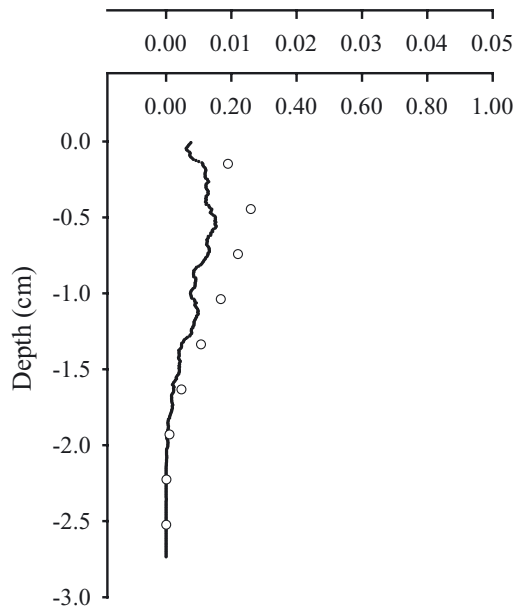

(b)

Relative concentration

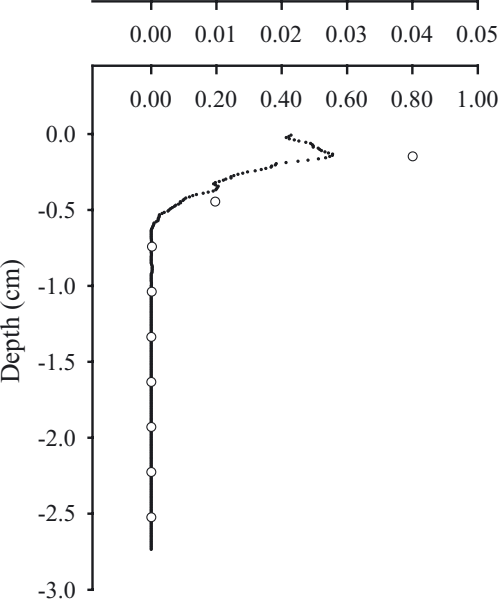

(e)

Relative concentration

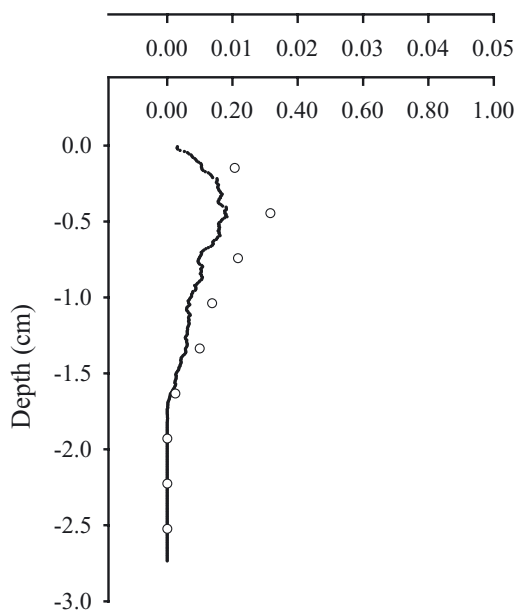

(h)

Relative concentration

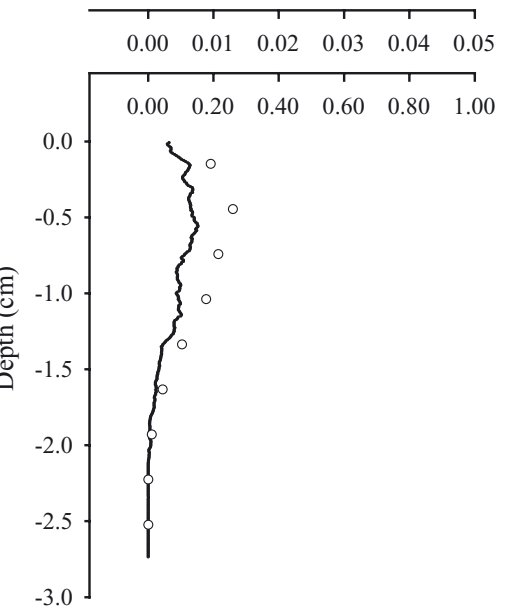

(c)

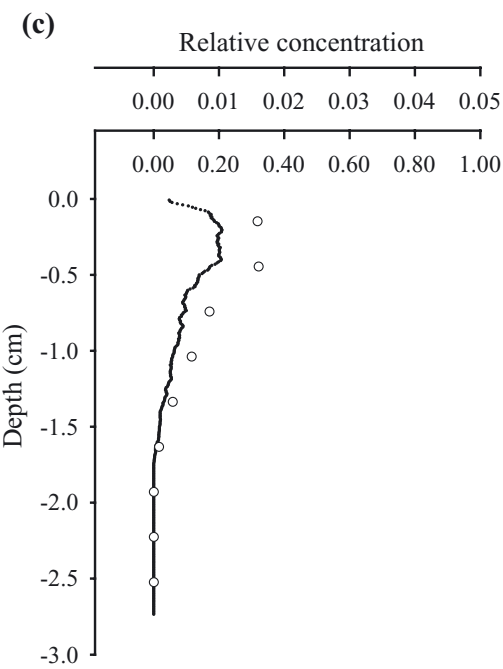

(f)

Relative concentration

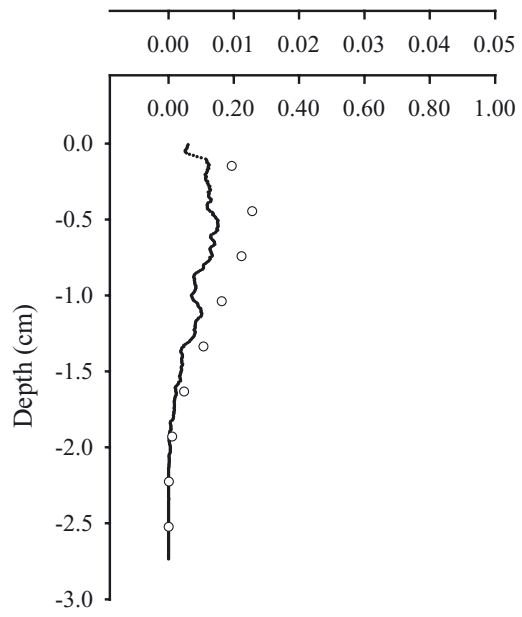

(i)

Relative concentration

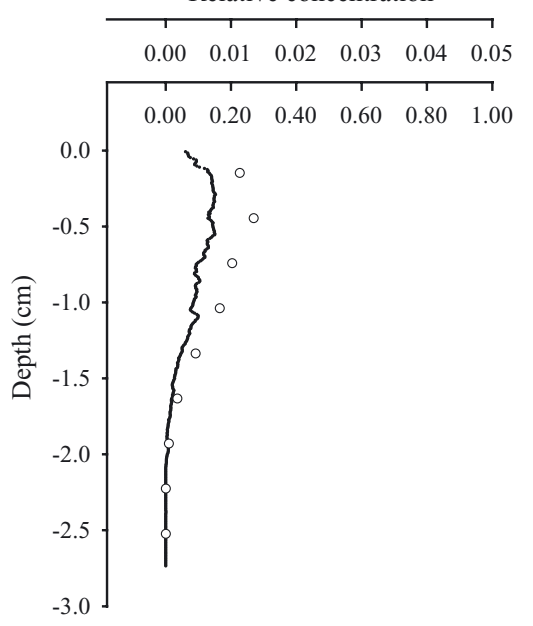

Fig. 4. Number of observed luminophore pixels (dots, upper $x$-axis) and equivalent aggregated data used for the model simulations (open circles, lower $x$-axis) plotted against sediment profile depth ( $y$-axis) for the images shown in Fig. 3. Data are expressed as relative concentrations 


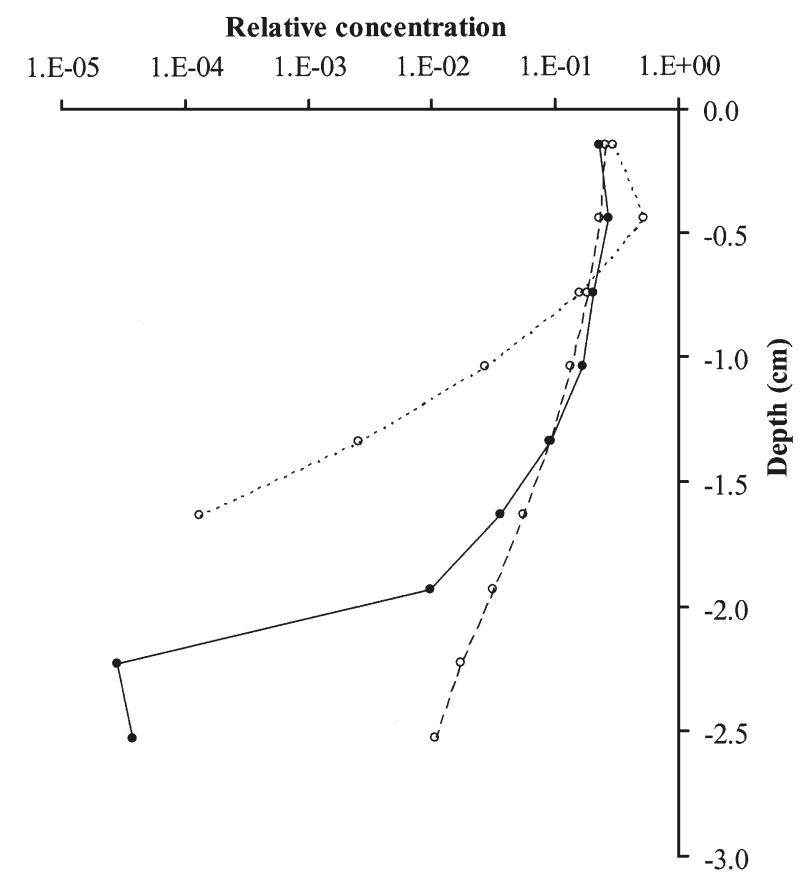

Fig. 5. Comparison of the observed luminophore activity profile (—- ) obtained from the final f-SPI (fluorescence sensitive time-lapse sediment profile imaging camera) image (Frame 97) after 950 min with the modelled predictions $(-\infty-)$ ) of the biodiffusive model (-..-) and the non-local model (-----)

output from $P_{\text {diff. }}$. The form of the $P_{\mathrm{nl}}$ also tracked that of $P_{\text {obs }}$ much more closely, allowing significant amounts of tracer to precede the tracer front, although there was increasing error at depths $>2.0 \mathrm{~cm}$ (Fig. 5).

Calculation of the reworking activity constant on a frame-by-frame basis (Fig. 6) revealed large differences in the extent of bioturbation during the time interval between each image. These discrete values of a fluctuated widely between each image step, spanning approximately 4 orders of magnitude $\left(10^{-6}\right.$ to $\left.10^{-2}\right)$ during the first $5 \mathrm{~h}$ of the f-SPI deployment and reducing to approximately 3 orders of magnitude $\left(10^{-3}\right.$ to $\left.10^{0}\right)$ for the remaining $11 \mathrm{~h}$

Fig. 6. Discrete reworking activity constant, $a$, calculated on a frame-by-frame basis. Fluctuations denote discrete periods of atypical bioturbation, either caused by increased $\left(a \rightarrow 10^{2}\right)$ or decreased $\left(a \rightarrow 10^{-6}\right)$ bouts of Hyas araneus activity. The non-local prediction for the final image is presented (dashed line) for comparison of the sequence. Nevertheless, a remained within an order of magnitude of the $P_{\mathrm{nl}}$ estimate based on the final image (i.e. $5.23 \times 10^{-2} \mathrm{~cm}^{-1} \mathrm{yr}^{-1}$; dashed line in Fig. 6) for $55 \%$ of the image steps, suggesting that this threshold was an appropriate descriptor of typical reworking activity levels. Departures in a away from this threshold appeared to be associated with discrete periods of atypical bioturbation, either caused by increased $\left(a \rightarrow 10^{2}\right)$ or decreased $\left(a \rightarrow 10^{-6}\right)$ bouts of Hyas araneus activity. Subsurface particle displacement caused by physical processes or other infaunal invertebrates appeared to be insignificant.

\section{DISCUSSION}

For establishing how the reworking activities of benthic infauna affect the storage and transport of sediment particles and porewater solutes, it is necessary to determine not only the rate of bioturbation, but also the mechanistic nature of biogenically mediated particle transport. Such information is necessary for conceptual mathematical models that aid in deciphering the precise characteristics of organismsediment relations. The combined approach adopted within our experiment provided a new means with which to non-invasively visualise and quantify in situ subsurface infaunal activity, at a spatial and temporal resolution previously not obtained for a particulate tracer. While the tracer profiles obtained allow even the smallest changes $(<78 \mu \mathrm{m})$ in particle distribution

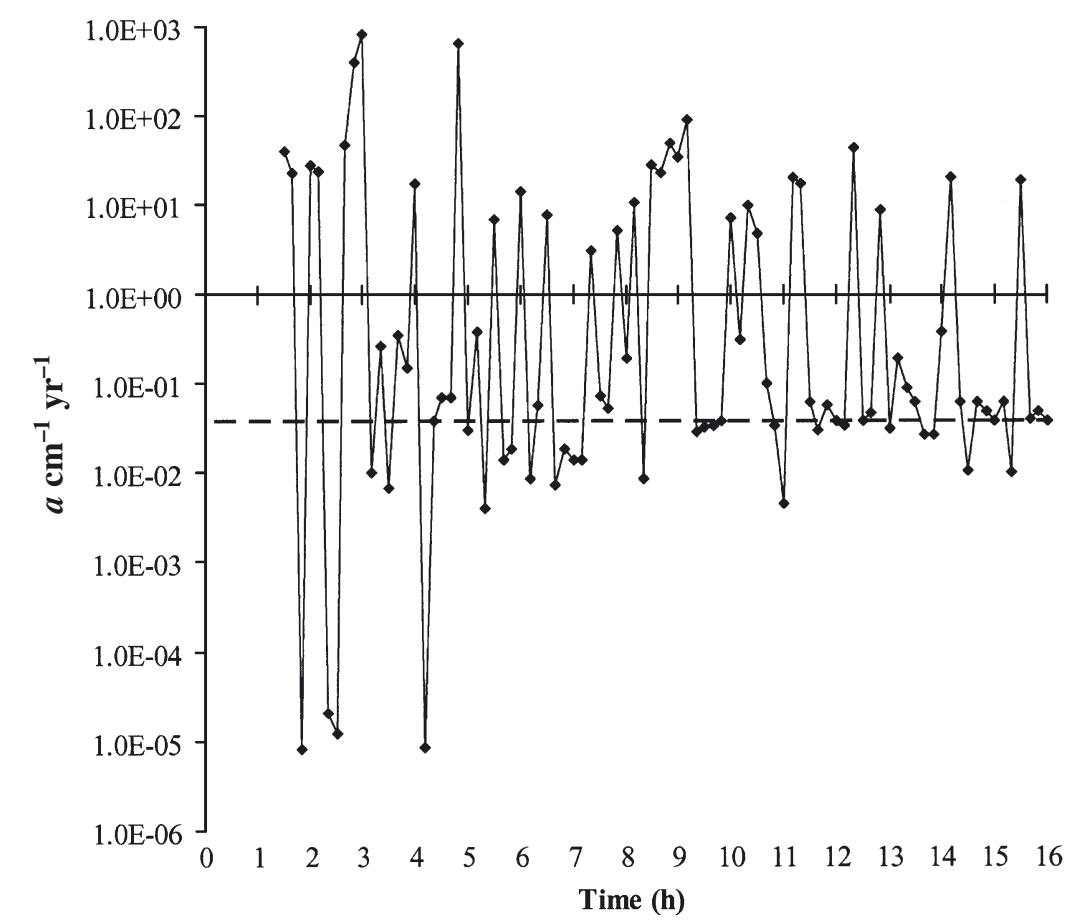


to be observed, the images provided the opportunity to consider unpredictable and discrete behavioural mixing events. This ability is not trivial, for it allows discrete events that cause particle redistribution over length steps greater than diffusional differences to be quantified and taken into account during the formalisation of suitable mathematical models of bioturbation.

The in situ f-SPI observations of infaunal behaviour revealed little activity below the sediment-water interface, despite high abundances of several species (e.g. Amphiura filiformis, A. chiajei, Nephtys hombergii) that are capable of considerable levels of bioturbation. Instead, the activities of the brachyuran crab Hyas araneus were clearly responsible for almost all of the observed luminophore particle redistribution. This species is commonly found at low densities (e.g. Mathieson \& Berry 1997) in temperate coastal regions (Dyer 1985), where it is an important member of the epibenthic scavenging community (Nickell \& Moore 1992a,b). While it is possible that the presence of the SPI assembly may have acted as a refuge and attracted this species to the camera, the patterns of bioturbation observed are nevertheless informative and of general applicability. Indeed, the f-SPI images revealed that $H$. araneus was seldom stationary and, although it did not actively burrow into the sediment profile, the continual repositioning of the walking legs resulted in a significant amount of particle displacement. The mechanics of each walking leg movement could be clearly visualised during playback of the time-lapse sequence, generating a piston-like redistribution of particles at an oblique angle relative to the sedimentwater interface. Preliminary measurements from the images estimate that as much as $\sim 0.30 \mathrm{~cm}^{3}$ of sediment may be displaced and transported to $\leq 2.5 \mathrm{~cm}$ depth each time one adult walking leg is repositioned. While these events may be punctuated with respect to time, they are certainly not rare, and their relative importance has not been previously appreciated; the nonlocal transport of particles from the sediment surface to depth is likely to have a disproportionate influence on the amount of recently settled organic material that becomes incorporated into the sediment profile. These short-lived discrete events may be, at least temporarily, of greater importance to local nutrient cycling budgets than the contribution from the background level of bioturbation.

The adopted image analysis routine successfully allowed the optical recovery of luminophores and subsequent calculation of $D_{\mathrm{b}}$. This process was rapid ( $<2$ wk for 96 profiles) and avoided the practical difficulties of tracer recovery associated with core slicing, although tracer enumeration from SPI imagery is likely to underestimate particle mixing because some luminophores may become horizontally displaced away from the camera face-plate and no longer be imaged. The values for $D_{\mathrm{b}}$ obtained with this technique are therefore likely to provide a conservative estimate of bioturbation. Despite this fact, the $D_{\mathrm{b}}$ values obtained here confirmed that bioturbation by Hyas araneus was extensive $\left(D_{\mathrm{b}}=1.26 \times 10^{2} \mathrm{~cm}^{2} \mathrm{yr}^{-1}\right)$ and consistent with the upper range of many estimates for entire subtidal communities (for review, see Matissoff 1982), although the images from the f-SPI indicated that a non-local mode of particle transport would form a more appropriate mechanistic description of crab activity. Tracers were transported rapidly over distances of $\mathrm{cm}$ in a manner that could not be related to a diffusive concentration gradient. Although bioturbation by decapod crustaceans has previously been modelled in a non-local manner, it has only been done for a specific set of circumstances. Boudreau \& Imboden (1987) and Gardner et al. (1987), for example, describe a form of particle redistribution induced by fiddler crabs as 'burrow and fill' or 'regeneration' mixing. In these models, vertical or near vertical tubes in the sediment profile are opened by the crab walking legs and filled with slumping material from a superficial surface layer. The model they used, however, assumed that the surface layer is not depleted by the burrowing activity of the organism. As this contrasts to the present study, where the upper layer of sediment is significantly depleted, a symmetric non-local model is more realistic. Using this method, the reworking activity constant, $a$, formed a much closer fit with the observed profiles of luminophore tracer. Moreover, comparison of the value of $a$ on a frame-by-frame basis provided a means with which to identify the frequency and magnitude of displacement events, i.e. discrete periods of atypical bioturbation, caused by either increased $\left(a \rightarrow 10^{2}\right)$ or decreased $\left(a \rightarrow 10^{-6}\right)$ bouts of $H$. araneus activity could be distinguished from background levels of bioturbation $\left(a=5.23 \times 10^{-2} \mathrm{~cm}^{-1} \mathrm{yr}^{-1}\right)$.

Consideration of behaviourally driven tracer mixing over short timescales is essential to the understanding of the fate of organic matter and other important constituents of the sediment profile. As the burial of particles is unpredictable, the adoption of a diffusive analogy averaged over extended time periods is likely to lead to an inaccurate classification of benthic activity (for exceptions, see Shull 2001, Shull \& Yasuda 2001). One alternative method has been the formulation of complex models tailored towards particular species or functional types (e.g. François et al. 1997, 2002); however, this approach cannot readily contribute to comparative syntheses of measurements made in different locales or at different times. Use of a simple non-local model, such as the one adopted in the present study, can simulate behaviourally driven tracer mixing with 
realistic length scales, whilst remaining applicable to more than one case study. An exponential function was used to determine exchange coefficients to simulate the greater exchange of particles between near and adjacent boxes than those between distant boxes. An iteratively determined activity constant allowed the strength of this mixing function to be varied to account for periods of faunal activity and quiescence. Our study demonstrates that f-SPI is capable of providing the necessary data on the frequency and length scales of discrete bioturbation events, allowing the parameters in bioturbation models to be directly related to infaunal activity. Combined with such readily available realtime data for tracer reworking, non-local modelling has the potential for exchange functions to be derived that closely mimic behaviourally driven particle redistribution. In this way, the necessary ethological information required to understand organism-sediment relationships can inform and improve capability in predictive modelling.

Acknowledgements. We are indebted for the provision of facilities and technical support received through the EU funded Access to Research Infrastructure (ARI) programme, hosted by Kristineberg Marine Research Station, Sweden. We thank A. Mustard (George Deacon Division, Southampton) for advice on optical filters. Constructive remarks on the manuscript from F. J. R. Meysman and 3 other anonymous referees are gratefully acknowledged. A copy of the f-SPI images, movies and image analysis macros can be obtained from the authors.

\section{LITERATURE CITED}

Aller RC (1982) The effects of macrobenthos on chemical properties of marine sediment and overlying water. In: McCall PL, Tevesz MJS (eds) Animal-sediment relations - the biogenic alteration of sediments. Topics in geobiology, Vol 2. Plenum Press, New York, p 53-102

Aller RC (1994) Bioturbation and remineralization of sedimentary organic matter: effects of redox oscillation. Chem Geol 114:331-345

Aller RC, Yingst JY (1985) Effects of the marine deposit-feeders Heteromastus filiformis (Polychaeta), Macoma balthica (Bivalvia) and Tellina texana (Bivalvia) on averaged sedimentary solute transport, reaction rates and microbial distributions. J Mar Res 43:615-645

Anderson FØ, Kristensen E (1991) Effects of burrowing macrofauna on organic matter decomposition in coastal marine sediments. Symp Zool Soc Lond 63:69-88

Berg P, Rysgaard S, Funch P, Sejr MK (2001) Effects of bioturbation on solutes and solids in marine sediments. Aquat Microb Ecol 26:81-94

Biles C, Solan M, Isaksson I, Paterson DM, Emes C, Raffaelli DG (2003) Flow modifies the effect of biodiversity on ecosystem functioning: an in situ study of estuarine sediments. J Exp Mar Biol Ecol 285/286:165-177

Blair NE, Levin LA, DeMaster DJ, Plaia G (1996) The short-term fate of fresh algal carbon in continental slope sediments. Limnol Oceanogr 4:1208-1219
Boudreau BP (1986) Mathematics of tracer mixing in sediments. II: Non-local mixing and biological conveyor belt phenomena. Am J Sci 286:199-238

Boudreau BP, Imboden D (1987) Mathematics of tracer mixing in sediments. III: The theory of non-local mixing within sediments. Am J Sci 287:693-719

Cadée GC (1976) Sediment reworking by Arenicola marina on tidal flats in the Dutch Wadden Sea. Neth J Sea Res 10: $440-460$

Crank J (1975) The mathematics of diffusion. Oxford University Press, Oxford

Diaz RJ, Cutter GR Jr (2001) In situ measurement of organism-sediment interaction: rates of burrow formation/abandonment and sediment oxidation/reduction. In: Aller JY, Woodin SA, Aller RC (eds) Organism-sediment interactions. Belle W. Baruch Library in Marine Science. University of South Carolina Press, Columbia, SC, p 19-32

Dyer MF (1985) The distribution of Hyas araneus (L) and Hyas coarctatus Leach (Crustacea, Decapoda, Brachyura) in the North sea and the Svalbard region. J Mar Biol Assoc UK 65(1):195-201

Fisher JB, Lick WL, McCall PL, Robbins JA (1980) Vertical mixing of lake sediments by tubificid oligochaetes. J Geophys Res 85:3997-4006

Forster S, Graf G (1995) Impact of irrigation on oxygen flux into the sediment: intermittent pumping by Callianassa subterranea and 'piston-pumping' by Lanice conchilega. Mar Biol 123:335-346

Forster S, Khalili A, Kitlar J (2003) Variation of nonlocal irrigation in a subtidal benthic community. J Mar Res 61:335-357

François F, Poggiale JC, Durbec JP, Stora G (1997) A new approach for the modelling of sediment reworking induced by a macrobenthic community. Acta Biotheor 45: 295-319

François F, Gerino G, Stora G, Durbec JP, Poggiale JC (2002) Functional approach to sediment reworking by gallery forming macrobenthic organisms: modelling and application with the polychaete Nereis diversicolor. Mar Ecol Prog Ser 229:127-136

Furukawa Y, Bentley SJ, Lavoie D (2001) Bioirrigation modelling in experimental benthic mesocosms. J Mar Res 59: $417-452$

Gardner LR, Sharma P, Moore WS (1987) A regeneration model for the effect of bioturbation by fiddler crabs on ${ }^{210} \mathrm{~Pb}$ profiles in salt marsh sediments. J Environ Radioact 5:25-36

Gerino M, Aller RC, Lee C, Cochran JK, Aller JY, Green MA, Hirschberg D (1998) Comparison of different tracers and methods used to quantify bioturbation during a spring bloom: 234-thorium, luminophores and chlorophyll a. Estuar Coast Shelf Sci 46:531-547

Gilbert F, Rivet L, Bertrand JC (1994) The in vitro influence of the burrowing polychaete Nereis diversicolor on the fate of petroleum hydrocarbons in marine sediments. Chemosphere 29:1-12

Gilbert F, Hulth S, Strömberg N, Ringdahl K, Poggiale JC (2003) 2-D optical quantification of particle reworking activities in marine surface sediments. J Exp Mar Biol Ecol 285/286:251-263

Gray JS (1974) Animal-sediment relationships. Oceanogr Mar Biol Annu Rev 12:223-261

Green MA, Aller RC, Cochran JK, Lee C, Aller JY (2002) Bioturbation in shelf/slope sediments off Cape Hatteras, North Carolina: the use of ${ }^{234} \mathrm{Th}, \mathrm{Chl}-\mathrm{a}$, and $\mathrm{Br}^{-}$to evaluate rates of particle and solute transport. Deep-Sea Res II 49: $4627-4644$

Hughes DJ, Ansell AD, Atkinson RJA (1996) Sediment bio- 
turbation by the echiuran worm Maxmuelleria lankesteri (Herdman) and its consequences for radionuclide dispersal in Irish Sea sediments. J Exp Mar Biol Ecol 195(2): 203-220

Jones SE, Jago CF (1993) In situ assessment of sediment properties by burrowing invertebrates. Mar Biol 115:133-142

Mahaut ML, Graf G (1987) A luminophore tracer technique for bioturbation studies. Oceanol Acta 10:323-328

Mathieson S, Berry AJ (1997) Spatial, temporal and tidal variation in crab populations in the Forth estuary, Scotland. J Mar Biol Assoc UK 77(1):167-183

Matisoff G (1982) Mathematical models of bioturbation. In: McCall PL, Tevesz MJS (eds) Animal-sediment relations - the biogenic alteration of sediments. Topics in geobiology, Vol 2. Plenum Press, New York, p 289-330

Meadows PS, Tufail A (1986) Bioturbation, microbial activity and sediment properties in an estuarine ecosystem. Proc R Soc Edinb B 90:129-142

Meysman FJR, Boudreau BP, Middelburg JJ (2003) Relations between local, nonlocal, discrete and continuous models of bioturbation. J Mar Res 61:391-410

Nickell TD, Moore PG (1992a) The behavioural ecology of epibenthic scavenging invertebrates in the Clyde sea area-laboratory experiments on attractions to bait in static water. J Exp Mar Biol Ecol 156(2):217-224

Nickell TD, Moore PG (1992b) The behavioural ecology of epibenthic scavenging invertebrates in the Clyde sea area-laboratory experiments on attractions to bait in moving water, underwater TV observations in situ and general conclusions. J Exp Mar Biol Ecol 159(1):15-35

Rhoads DC (1974) Organism-sediment relations on the muddy sea floor. Oceanogr Mar Biol Annu Rev 12:263-300

Editorial responsibility: Otto Kinne (Editor),

Oldendorf/Luhe, Germany
Rhoads DC, Boyer LF (1982) The effects of marine benthos on physical properties of sediments. A successional perspective. In: McCall PL, Tevesz MJS (eds) Animal-sediment relations - the biogenic alteration of sediments. Topics in geobiology, Vol 2. Plenum Press, New York, p 3-52

Rhoads DC, Cande S (1971) Sediment profile camera for in situ study of organism-sediment relations. Limnol Oceanogr 16:110-114

Richter R (1952) Fluidal-texture in Sediment-Gesteinen und ober Sedifluktion überhaupt. Notizbl Hess Landesamtes Bodenforsch Wiesbaden 3:67-81

Rowden AA, Jones MB, Morris AW (1998) The role of Callianassa subterranea (Montagu) (Thalassinidea) in sediment resuspension in the North Sea. Cont Shelf Res 18:1365-1380

Sandnes J, Forbes T, Hansen R, Sandnes B, Rygg B (2000) Bioturbation and irrigation in natural sediments, described by animal-community parameters. Mar Ecol Prog Ser 197: 169-179

Shull DH (2001) transition-matrix model of bioturbation and radionuclide diagenesis. Limnol Oceanogr 46:905-916

Shull DH, Yasuda M (2001) Size-selective downward particle transport by cirratulid polychaetes. J Mar Res 59:453-473

Solan M, Kennedy R (2002) Observation and quantification of in situ animal-sediment relations using time-lapse sediment profile imagery (t-SPI). Mar Ecol Prog Ser 228: 179-191

Wheatcroft RA, Jumars PA, Smith CR, Nowell ARM (1990) A mechanistic view of the particulate biodiffusion coefficient: step lengths, rest periods and transport directions. J Mar Res 48:177-207

Wheatcroft RA, Olmez I, Pink FX (1994) Particle bioturbation in Massachusetts Bay: preliminary results using a new deliberate tracer technique. J Mar Res 52:1129-1150

Submitted: September 19, 2003; Accepted: January 27, 2004 Proofs received from author(s): March 26, 2004 